\title{
Left ventricular platelet deposition after acute myocardial infarction
}

Sir,

Verheugt and colleagues $(1984 ; 52: 490-6)$ have made a solid new addition to the many previously reported differences ${ }^{1}$ between $Q$ wave and non- $Q$ wave myocardial infarction: the selective tendency for left ventricular thrombosis in the former. Since the presence of a $Q$ wave cannot reliably distinguish anatomically transmural from non-transmural infarction ${ }^{12}$ it is unfortunate that the authors have continued the standard, but erroneous labelling. (It may well be that the majority of $Q$ wave infarcts are indeed anatomically transmural and many of the non- $Q$ wave infarcts non-transmural, but the electrocardiogram is not able to distinguish these with certainty.)

This would be a terminological quibble if it were not that mislabelling can cloud concepts. By avoiding the inaccurate label perhaps further efforts will be directed at distinguishing further real, and it is to be hoped, fundamental differences between $Q$ wave and non- $Q$ wave infarcts.

David H Spodick, Division of Cardiology,

St Vincent Hospital, Worcester, Massachusetts, USA.

\section{References}

1 Spodick DH. Q-wave infarction versus ST-infarction: nonspecificity of ECG criteria for differentiating transmural and nontransmural lesions. Am f Cardiol 1983; 51: 913-5.

2 Phibbs B. "Transmural" vs "subendocardial" myocardial infarction: an electrocardiographic myth. $\mathcal{F}$ Am Coll Cardiol 1983; 1: 561-4.

\section{Notices}

\section{Body surface mapping}

The 3rd International Symposium on body surface mapping will be held from 11 to 14 June 1985 at the University of Nijmegen, The Netherlands. Further information may be obtained from: Dr R Th van Dam, Department of Cardiology, Geert Grooteplein Zuid 8, 6525 AG Nijmegen, The Netherlands.

\section{British Cardiac Society}

The Annual General Meeting for 1985 will take place in Birmingham on 17 and 18 April 1985, and the closing date for receipt of abstracts was 8 January 1985.

The Autumn Meeting will be held at the Wembley Conference Centre, London, on 26 to 28 November 1985 , and the closing date for receipt of abstracts will be 1 August 1985.

\section{Unstable angina revisited}

A clinical review of unstable angina organised by the Thoraxcenter, Erasmus University, Rotterdam, the Interuniversitary Cardiological Institute, Utrecht, The Netherlands, and the Toronto General Hospital, Toronto, Canada, is to be held in Rotterdam from 23 to 25 May 1985. Further details may be obtained from: Professor P G Hugenholtz, Thoraxcenter Bd 406, Erasmus University Rotterdam, PO Box 1738, 3000 DR Rotterdam, The Netherlands.

\section{Non-invasive cardiovascular dynamics}

The XIII European congress organised by the European Society for non-invasive cardiovascular dynamics will be held in Brescia, Italy, from 22 to 25 April 1985. Further details may be obtained from: Dr G Orlando, St Orsola Hospital, Via Vittorio Emanuele 27, 25122 Brescia, Italy. 